\section{REMOVAL OF FOREIGN BODIES FROM THE EAR, AND COUGH FROM} AURAL IRRITATION.

By JOH N CLELA ND, M.D. EDIN.,

PROFESSOR OF ANATOMY AND PHYSIOLOGY, QUBEN'S COLLEGE, GALWAY.

Lookina over the chapter on "Foreign Bodies in the War" in the recently translated work of von Tröltsch, I remark the objection made to instruments as being liable to drive the offending body inwards, and the preference given to a "properly directed stream of water," and am led to bring under notice an observation which I made twelve years ago, serving to show what the proper direction is in which an instrument should be made to act. When I was demonstrator in Glasgow, a student came to me in much alarm with a pea in the auditory meatus, which had been flung in a class room, and had been driven far in towards the membrana tympani by the efforts of one of his fellow. students to remove it. It fitted sufficiently accurately that there was no space for the introduction of an instrument behind it. I had no instrument beside me but a straight needle for microscopic purposes. I touched the upper margin of the pea with this, endeavouring to introduce the needle bebind the pea, when the pea rolled somewhat and receded. It then occurred to me to place the point of the meedle beneath the pea, and, to my great surprise, I had scarcely begun to insinuate the point of the needle when the pea flew out with great violence. Anyone may repeat the experiment, as I have done, with a pea, a tube, and a needle, and may easily arrive at the explanation of what happened in the case which I have mentioned. If the needle be placed above the pea, it presses on the uppermost part of the sphere. By a movement of combined pressure and withdrawal the pea may then be made to roll outwards for a little distance; but in this movement needle and pea move together, so that the point of the needle, continuing to press on the portion originally uppermost but now rolled outwards, ceases immediately to act in a purely downward direction, and jerks the pea back towards the membrana as soon as the increasing pressure inwards exceeds the resistance of friction against the floor of the tube. But if the point of the needle be placed below the pea, it raises it up; and if it has been insinuated in the smallest degree beyond the lowest part of the sphere, and be on a higher level than the handle, the pea tends to roll out over it. It is not, however, essential that the point of the needle be on a higher level than the handle, provided only that the needle be properly insinuated in ; for as soon as the handle is depressed so far that the point is at all inclined towards the roof of the tube, the pea is placed between two inclined planes, from between which it is expelled with force.

The circumstance thut in thr same chapter of the work above referred to allusion is made to the occurrence of coughing from irritation in the ear leads me, while pen is in hand, to notice a curious enough example of this. The membrana tympani of my own right ear was perforated hy suppuration in scarlatina at three years of age, and otorrboe continued for nine years. There is one particular spot of limited extert in the floor of the meatus, about an inch from the ourside, and not extending inwards to the membrana, nor at all to the sides or roof, which, when pressed on by an instrument, produces uncontrollable and most violent coughing. It is not more tender to the touch than the other parts of the meatus equally far in, or the corresponding parts in the other ear, which produce no such phenomenon. It is of some importance, physiologically, to note, what may not have been observed in such cases hitherto, that the immediate effect of the aural irritation is a peculiar sensation in the throat, referred to the back of the larynx; that is to say, it seems further back than the tickling sensation which produces an ordinary cough. This, therefore, is not a simple reflex action in which the irritation conveyed by one sensory nerve acts immediately on a motor centre governing another part. A precisely similar phenomenon may be occasionally observed when the pressing open of an acne on the ridge of the nose causes the sensation which brings on a sneeze.

Vicarscroft, Galway.

\section{SYMPTOMS OF POISONING AFTER A COMPARATIVELY SMALL DOSE OF HENBANE.}

\author{
Br W. MACFIE CAMPBELL, M.D.
}

Mr. A. B-, merchant, aged about sixty years, had been prescribed a mixture containing one drachm and a half of tincture of henbane, in each dose of half an ounce. After one dose had been taken the medicine was countermanded, but the bottle still remained in the house. Feeling unwell some days later, and not knowing or noticing the proper dose, he helped himself to between one ounce and a half and two ounces of the mixture. This was at 3.30 P.M., and at 6.30 P.M. he became excited, and incoherent in his speech, wandered purposelessly about the house, muttering and touching things, as though suspicious of those about him. He then lay down upon a sofa, and appeared drowsy, but very restless. Under the idea of calming him, his wife administered another dose of the same mixture (a drachm and a half of tincture of hyoscyamus), with the effect of aggravating the symptoms. He became delirious; saw policemen coming into the house; heard them speaking about him in the hall; his face became flushed; his hands were constantly in motion, seemingly trying to rub his face or brush something away. He was very irritable, and continually muttering to himself.

I was sent for at $8.40 \mathrm{P} \mathrm{M}$, and found him in the following state :-Face and neck flushed, swollen and dry; extremities cold; pulse small and rapid; pupils slightly dilated; tongue and mouth parched; breathing natural. He appeared drowsy, but restless, constantly shifting his position. He did not attempt to answer any questions, but occasionally muttered a few disjointed words.

Having attended him for dipsomania, I feared that what I had repeatedly warned him of-delirium tremens-was commencing; but, on inquiry, heard about the return to the discarded mixture. His son said he saw him take about a wineglassful ; and on examining the bottle, six doses were gone, so that he had taken during the day from seven to seven and a half drachms of the tincture. Allowing for errors, the first dose could not have exceeded six drachms. This explained his otherwise curious symptoms, and enabled me to set his friends' mind at ease abont delirium tremens. Having vomited pretty freely, his feet were placed in a hot-water-and-mustard batb, a pint of strong tea was given him, and he was put to bed. By 11 P M. his pulse was stronger, he answered questions sensibly, and though still drowsy, was in a fair way to recovery. He passed a good night and awoke almost quite well, his only after-symptom being flushing and itching of the face, which persisted for some days. Curiously enough, the day before was to him an entire blank; he remembered nothing from the time he took the medicine till the next morning.

These symptoms are very nearly those described by Dr. Taylor, in his "Medical Jurisprudence," as following a dose of henbane not sufficient to cause death. Dr. Taylor does not state what that duse is, but this case shows that a drug looked upon by many as harmless may in some constitutions produce alarming effects.*

I may add that Mr. B- takes opium very badly, the only sedative which I have found to agree with him being chloral.

Livcrpool.

* See also case described by Mr. White, of Regent's-park, in Tra LavaeT, July $5 \mathrm{th}, 1873$, in which the dose was eleven drachms.

Bequests \&c. to Medical Charities. - Mr. John Pdine, of Patcham-place, near Brighton, has bequeathed $\$ 5000$ each to the Sussex Cunty Hospital, Brighton, and the Brighton and Hove Dispensary, \&l000 to the Asylum for the Blind, Brighton, and $\$ 1000$ to the Cancer Hospital, Brompton. Mrs. Coombe, widow of Mr. Thomas Coombe, of the Clarendon Press, has offered $£ 5000$ for the erection of a ward for children at the Radcliffe Infirmary, Oxford. Mr. William Lambert, of Fincbley and Monmouth, has bequeatbed $\$ 500$ to the Monmouth Hospital. 